\title{
THE ACTION AND INTERACTION OF CALCIUM AND ALKALI CHLORIDES ON EGGS OF LIMNAEA STAGNALIS AND THEIR CHEMICAL INTERPRETATION
}

\author{
W. L. M. G EI LEN K I R CH E N \\ Zoological Laboratory, University of Utrecht, Utrecht, the Netherlands \\ Received May 27, 1963
}

ThE treatment of eggs of Limnaea stagnalis with alkali chlorides for $24 \mathrm{hr}$ after first cleavage causes death or abnormal development, depending on the concentrations.

Raven et al. [8] found that the relationship between mortality and ion concentration is similar for all alkali metal ions. By plotting direct mortality (mortality before gastrulation) against the logarithm of concentration, sigmoid curves are obtained (Fig. 1). For each ion a particular concentration range is found, within which mortality sharply increases. The sequence of effective concentrations is: $\mathrm{Li}<\mathrm{Cs}<\mathrm{Rb}<\mathrm{K}<\mathrm{Na}$. Similar series have been described by Bungenberg de Jong [1], as specific for the reversal of charge of phosphate colloids. Using this analogy, Raven et al. [8] identified the action of alkali metal ions on egg cells with in vitro action of the same ions on phosphate colloids. They formulated the following statement: "The cations of the outer medium, by being absorbed on the phosphatide particles in the egg cortex, change the latter's properties; at a certain concentration of the cation the normal physiological properties of the cortex arc altered in such a way that normal development is no longer possible, and death ensues".

Geilenkirchen [4] treated separately and substantiated the hypotheses implicit in this statement: (1) the leading role of the cortex in development; (2) identity of the morphogenetically active cortex with a physiologically active cortex; (3) phosphate colloids in the form of phosphatides acting as basic components of the cortex and as cation-adsorbing substances; and (4) specificity of the sequence of alkali metal ions for reversal of charge of phosphate colloids. For a preliminary approach the cortex, which, according to Elbers [3], may be identified with the cell membrane may thus be regarded as being composed of oriented phospholipids complexed with proteins. Evidence was provided that $\mathrm{Ca}^{2+}$ ions are indispensable in the cell membrane 
for its structure and proper functioning and thus for the development of Limnaea eggs [4].

In view of the hypothesis given above the cell membrane may be identified with a phosphate colloid containing a certain amount of calcium. In terms of

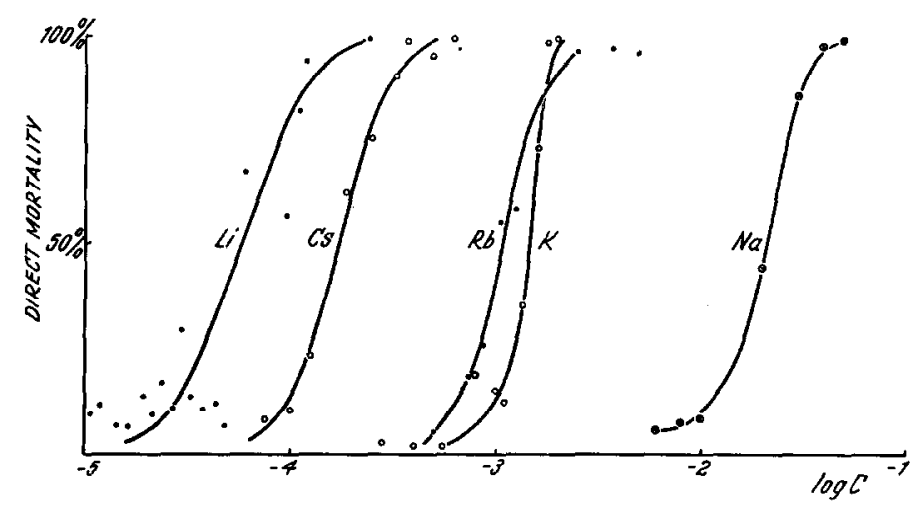

Fig. 1.-The relation between direct mortality and concentrations of lithium, sodium, potassium, rubidium and caesium chloride.

Abscissae: log. concentration (in equiv. per L.).

Ordinates: percentage mortality.

a reversal of charge curve, the membrane's phosphate colloid is in a hypothetical charge condition $\mathrm{A}$ on the curve in Fig. 2. Withdrawal of $\mathrm{Ca}^{2+}$ from the colloid will effect a change in charge towards a condition indicated by $\mathrm{B}$. This may influence the structure and functioning of the cell membrane. It was indeed found that withdrawal of too much calcium impedes development [4]. On the other hand, addition of $\mathrm{Ca}^{2+}$ may effect a change of charge from A towards $\mathrm{C}$, the point of charge reversal. $\mathrm{CaCl}_{2}$ causes an increasing death rate according to an S-shaped curve at concentrations from 2.5 to $3.5 \times 10^{-2} \mathrm{M}$ $[4,11]$. If we compare these concentrations with the calcium concentrations for reversal of charge of phosphate colloids in vitro according to Bungenberg de Jong et al. [1], they appear to be of the same order of magnitude. Therefore it is supposed that near the concentration of $3 \times 10^{-2} \mathrm{M} \mathrm{CaCl}_{2}$ in the medium the condition of the membrane has been shifted from $A$ so far in the direction of $C$ that a certain amount of charge compensation prevails which is harmful to the structure and/or function of the cell membrane. The ultimate result is death.

The hypothesis of Raven et al. [8] is based on the similarity of the alkali metal ion spectrum for reversal of charge of phosphate colloids and for mortality of egg cells. But the experiments of Bungenberg de Jong et al. [1] 
show that alkali metal ions cause reversal of charge only at concentrations much higher than $\mathrm{CaCl}_{2}$, or divalent ions in general. With egg cells, however, it is invariably found that alkali ions are lethal at concentrations much lower than the lethal concentration range of $\mathrm{CaCl}_{2}$. Therefore, the sequence of

Fig. 2.-Hypothetical curve of charge changes of a phos ${ }^{-}$ phate colloid in the cell membrane.

Abscissae: concentration of $\mathrm{Ca}^{2+}$ ions in the egg medium. Ordinates: charge in arbitrary units.

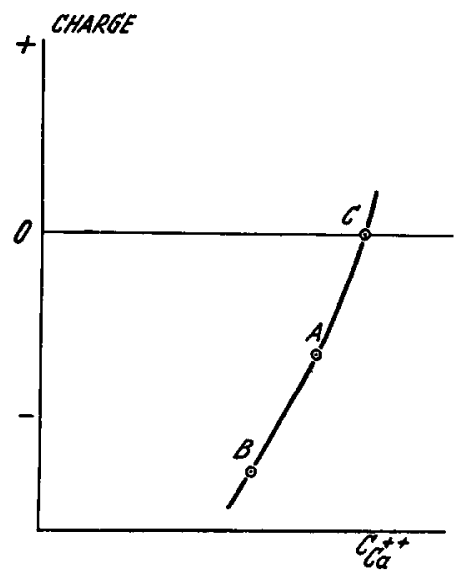

lethal concentrations found for alkali metal ions cannot be directly correlated with reversal of charge of phosphate colloids of the egg cell.

As was mentioned above, the cell membrane can be considered to contain a phosphate colloid with a certain amount of calcium fixed onto it. The treatment of eggs in a solution of an alkali chloride is therefore comparable to an in vitro experiment in which the influence of the addition of alkali salts to the system phosphate colloid $+\mathrm{Ca}^{2+}$ is investigated. According to Bungenberg de Jong [1], we may expect in that case: (1) a lowering of the activity coefficient of calcium by the added anions and (2) at increasing alkali metal ion concentrations, a fixation of alkali metal ions on the colloid. In the experiments on eggs treated with alkali chlorides alone, we have to do with a low concentration of calcium. We assume that alkali chlorides will lower the activity coefficient of calcium. This effect (which is due to the anions) will be equal for all alkali chlorides at equal concentrations. But the fixation of alkali metal ions on the membrane depends on the nature of these ions. The readiness with which a certain ion is fixed on the colloid is inversely related to its reversal of charge concentration. Thus it seems probable that the series $\mathbf{L i}<\mathrm{Cs}<\mathrm{Rb}<\mathrm{K}<\mathrm{Na}$ for death rate is the expression of the different rate of fixation of the cations on the phosphate colloid, which is concentration-dependent. 
The following hypothesis was therefore proposed to account for the observed phenomena [4].

(1) At a concentration of $\mathrm{Ca}^{2+}$ ions in the medium around the egg near $3 \times 10^{-2} M$, so many $\mathrm{Ca}^{2+}$ ions become fixed on a phosphate colloid in the cell membrane that the charge of the membrane will reach a value at or near the point of charge reversal. This change of charge will influence the structure and/or function of the cell membrane and the egg dies.

(2) If the concentration of alkali metal ions in the environment of the egg passes a certain limit, these ions will be fixed on a phosphate colloid in the cell membrane in competition with the calcium present. Again the egg will die, now as a result of the fixation of alkali metal ions and/or the expulsion of $\mathrm{Ca}^{2+}$ ions. The effectivity of fixation at equal concentrations of alkali metal ions in the medium decreases in the order $\mathrm{Li}>\mathrm{Cs}>\mathrm{Rb}>\mathrm{K}>\mathrm{Na}$.

As a further test for the hypothesis that the egg cell membrane can be identified with a phosphate colloid system, we can investigate whether known effects of combinations of ions on phosphate colloids in vitro are paralleled by similar effects in egg cells.

Bungenberg de Jong et al. [1] found in reversal of charge experiments with phosphate colloids that the concentration of $\mathrm{CaCl}_{2}$ needed for charge reversal increases by the addition of a small quantity of alkali salt.

In the egg cells concentrations of $\mathrm{CaCl}_{2}$ between 2.5 and $3.0 \times 10^{-2} M$ cause an increasing mortality. This was explained as a change of charge of a phosphate colloid in the cell membrane to a value near the point of charge reversal. If this is true, addition of alkali salts must shift the noxious effects of $\mathrm{CaCl}_{2}$ to higher concentrations. In this paper experiments with $\mathrm{LiCl}, \mathrm{NaCl}$, $\mathrm{KCl}$ and $\mathrm{CsCl}$ are described to test this point.

The second part of our hypothesis deals with fixation of alkali metal ions in competition with calcium present at the membrane. It is obvious that, if such a competition docs exist, addition of $\mathrm{Ca}^{2+}$ to the medium will antagonize the fixation of alkali metal ions. Indications of this have often been found $[2,8,11]$.

In this paper an extensive study is made of the antagonism of $\mathrm{CaCl}_{2}$ with respect to $\mathrm{LiCl}, \mathrm{NaCl}, \mathrm{KCl}$ and $\mathrm{CsCl}$.

The experiments for this study were made in cooperation with H. L. dc Beaufort and J. A. Leussink for LiCl, Miss F. C. J. C. Eversman and Miss L. P. M. Timmermans for $\mathrm{CsCl}$, A. J. Leeuwenberg for $\mathrm{KCl}$, and $\mathrm{A}$. F. Schreurs and W. de Rover for $\mathrm{NaCl}$. 


\section{MATERIAL AND METHODS}

Eggs and egg capsules.-Egg masses of Limnaea stagnalis are obtained by transferring adult snails kept in water at $20^{\circ} \mathrm{C}$ to water at $25^{\circ} \mathrm{C}$ and additional stimulation with leaves of Hydrocharis morsus-ranae L. This method has been described by Raven and Bretschneider [9].

An egg mass of Limnaea consists of up to 150 egg capsules, each containing, as a rule, one egg. The diameter of an uncleaved egg cell is about $0.12 \mathrm{~mm}$, and the volume of a capsule about $1 \mathrm{~mm}^{3}$, though differing quite a lot from egg mass to egg mass. Each egg cell is suspended within a perivitelline fluid (capsule fluid) surrounded by the capsule membrane. A vitelline membrane adheres firmly to the surface of the egg cell proper. In all experiments the eggs are treated and reared within their capsules.

Standard procedure.-From previous experience [8], it is known that, in order to obtain comparable results in experiments with ions, a strict standardization of experimental conditions is needed. All ion experiments described in this paper were made according to the following standard procedure [4].

Pretreatment: The egg masses are deposited in tapwater. Shortly before first cleavage is expected, the egg capsules are freed from the egg mass jelly. The capsules of each egg mass are kept together in a salt dish with tapwater until part of the eggs reach the first cleavage stage (stage $1-2,[6]$ ). Then they are ready for treatment. Room temperature is maintained during pretreatment.

Treatment: In experiments with single ions or mixtures, the effect of different concentrations is compared. Treatment takes place at $25^{\circ} \mathrm{C}$ for $24 \mathrm{hr}$ after first cleavage. During this time untreated eggs at $25^{\circ} \mathrm{C}$ reach a stage of about 200 cells (beginning of gastrulation).

In any single experiment a series of concentrations is used, giving a number of treatment groups designated 0 (dist. water, control), A, B, C, D, etc. In this way death-rate curves for $\mathrm{CaCl}_{2}$ and alkali chlorides are determined. Then the influence of $\mathrm{CaCl}_{2}$ on death rate caused by an alkali chloride is tested. If 0 (dist. water), $\mathrm{A}$ and $\mathrm{B}$ are $\mathrm{CaCl}_{2}$ concentrations and 0 (dist. water), a, b, c, $d$ and e are concentrations of LiCI. The possible combinations are tested in one experiment according to the scheme.

$\begin{array}{ccccccc}\underset{\mathrm{CaCl} \ldots}{\mathrm{CaCl}} & \text { o } & \text { a } & \text { b } & \text { c } & \text { d } & \text { e } \\ \mathrm{O} & \times & \times & \times & \times & \times & \times \\ \mathrm{A} & \times & \times & \times & \times & \times & \times \\ \mathrm{B} & \times & \times & \times & \times & \times & \times\end{array}$

In successive experiments different concentrations of both ions are tested. In experiments to analyze the influence of an alkali chloride on death caused by $\mathrm{CaCI}_{2}$ the scheme is reversed. The total number of treatment groups amounts in our experiments to 20. In order to obtain comparable treatment groups, all groups should contain comparable egg material. In this respect egg cells from one egg mass are regarded as comparable units. Since about 20 eggs per group are used as a rule, more than one egg mass (50-150 eggs) per experiment is needed. 
The eggs of the mass which first reaches first cleavage are equally distributed among the treatment groups. The next mass to cleave is distributed in the same way; a third egg mass likewise, and so on. Sufficient egg masses are used to ensure that the total number of capsules per treatment group numbers between 15 and 20. Care is taken that the time interval between cleavages in the first and the last egg mass does not exceed $30 \mathrm{~min}$.

The eggs are treated in stoppered standard glass tubes with flat bottoms, $2.5 \mathrm{~cm}$ in diameter, with a volume of $30 \mathrm{ml}$. A fixed volume $(10 \mathrm{ml})$ of treatment solution is used. In this way a standard relation between number of eggs and volume of solution is achieved. The wide tubes with flat bottoms guarantee free contact of each capsule with the treatment solution.

The salts used were all chlorides of p. a. quality. Solutions were always made with glass-distilled water. Solutions were made by diluting stock solutions, according to analytical chemical standards. In case of mixtures of salts, equal volumes of double concentrated solutions were mixed.

WASHING: Immediately after treatment, the treatment solution is poured off. The tubes containing the eggs are washed three times with tapwater and finally filled with $20 \mathrm{ml}$ of tapwater and kept for another $24 \mathrm{hr}$ at $25^{\circ} \mathrm{C}$.

Rearing: After washing, the capsules are dried on filter paper and laid out on a semi-sterile $2 \%$ agar-agar gel in a Petri dish. For each experiment one dish is used. The arrangement of the capsules on the agar is such that the capsules of all treatment groups are distributed comparably from center to circumference of the Petri dish. The separate capsules are spaced at relative distances of a few $\mathrm{mm}$. The agar gel is kept moist by water contained in slits in the agar, which, in addition, separate the treatment groups. The eggs are now cultured at $25^{\circ} \mathrm{C}$ for five or six days.

Developmental disturbances and their evaluation.--The development of the embryos is followed from day to day, and a record is kept of each egg until a stage at which the eyes, in normal embryos, are well developed. In all seven grades of developmental disturbances are distinguished.

DEATH FIRST PERIOD: Under this heading all those embryos are included in which death occurs without being preceded by any visible morphological abnormality. These embryos die before or during the gastrula stage. Death first period parallels the term 'direct mortality' introduced by Raven et al. [8].

DEATH SECOND PERIOD: All embryos which develop further than the gastrula stage but die without showing specific morphological abnormalities are classed in this category.

Exogastrulation: Exogastrulae observed in Limnaea experiments are vesicular embryos, in which the invagination of the archenteron is suppressed. In these abnormalities no further development is observed and death usually ensues within a few days.

UNSPECIFIC MALFORMATIONS: In this group all embryos are included which show an abnormal development but which cannot be described as head malformations. They are as a rule teratomorphic or hydropic embryos.

Head malformations: As head malformations are classed all microphthalmic, monophthalmic, synophthalmic, triophthalmic, cyclopic and anophthalmic embryos and no specification is made. 
Normal: All embryos showing a normal ontogeny are classed as normal. This category may also include cases where development is delayed but nevertheless normal in result.

\section{RESULTS}

The interaction of $\mathrm{CaCl}_{2}$ and $\mathrm{LiCl}-\mathrm{CaCl}_{2}$ causes an increasing death rate belween the concentrations 2.5 and $3 \times 10^{-2} M$ [4]. LiCl causes an increasing death rate between the concentrations $5 \times 10^{-5}$ and $1.5 \times 10^{-4} M[8]$. Data by Elbers [2], de Vries [11] and Raven et al. [8] on the interaction of $\mathrm{CaCl}_{2}$ and $\mathrm{LiCl}$, tested with a few combinations of concentrations only, show that nonnoxious $\mathrm{CaCl}_{2}$ concentrations antagonize the effects of $\mathrm{LiCl}$. Starting from these data, a wide array of combinations of the two salts have been tested on different numbers of eggs, as shown in Table I. The total number of eggs

TABLE I. Numbers of eggs used at the various concentration combinations.

\begin{tabular}{|c|c|c|c|c|c|c|c|c|c|c|c|}
\hline \multirow[b]{2}{*}{$\mathrm{CaCl}_{2}$} & \multirow[b]{2}{*}{0} & \multicolumn{3}{|c|}{$\times 10^{-5} M$} & \multicolumn{3}{|c|}{$\times 10^{-4} M$} & \multicolumn{2}{|c|}{$\times 10^{-3} M$} & \multicolumn{2}{|c|}{$\times 10^{-2} M$} \\
\hline & & 2.4 & 4.8 & 9.6 & 1.9 & 3.8 & 7.7 & 1.5 & 3.1 & 1.2 & 2.5 \\
\hline 0 & 878 & 219 & 685 & 616 & 628 & 570 & 547 & 452 & 33 & 16 & 16 \\
\hline $0.6 \times 10^{-5} M$ & 33 & 34 & 34 & 34 & 33 & & & & & & \\
\hline 1.2 & 119 & 88 & 64 & 65 & 34 & & & & & & \\
\hline 2.4 & 137 & 106 & 115 & 62 & 64 & & & & & & \\
\hline 4.8 & 106 & 70 & 100 & 31 & 30 & & & & & & \\
\hline 9.6 & 124 & 71 & 69 & 31 & 49 & & & & & & \\
\hline $1.9 \times 10^{-4} M$ & 219 & 50 & 102 & 84 & 71 & 64 & 65 & 33 & 33 & & \\
\hline 3.8 & 165 & 48 & 50 & 50 & 64 & 64 & 99 & 46 & 33 & & \\
\hline 7.7 & 211 & 63 & 97 & 50 & 49 & 31 & 69 & 63 & 33 & & \\
\hline $1.5 \times 10^{-3} M$ & 198 & 81 & 81 & 95 & 64 & 30 & 60 & 35 & & & \\
\hline 3.1 & 149 & 53 & 53 & 46 & 54 & 29 & 51 & 35 & & & \\
\hline 6.1 & 194 & 53 & 95 & 81 & 97 & 65 & 64 & 68 & & 13 & 15 \\
\hline 9.2 & 68 & & 64 & 68 & 68 & 68 & 68 & 68 & & & \\
\hline $1.2 \times 10^{-2} M$ & 122 & 30 & 122 & 123 & 124 & 126 & 120 & 94 & & & \\
\hline 1.8 & 126 & & 124 & 124 & 119 & 119 & 122 & 120 & & & \\
\hline 2.5 & 217 & 29 & 153 & 174 & 203 & 187 & 187 & 126 & & 15 & 14 \\
\hline 2.8 & 131 & & 131 & 131 & 129 & 131 & 129 & 139 & & & \\
\hline 2.9 & 38 & & 39 & 39 & 34 & 39 & 38 & & & & \\
\hline 3.1 & 102 & & 101 & 100 & 100 & 100 & 100 & 80 & & & \\
\hline 3.2 & 39 & & 38 & 39 & 39 & 37 & 38 & & & & \\
\hline 3.3 & 73 & & 73 & 71 & 73 & 71 & 73 & 71 & & & \\
\hline 3.5 & 39 & & 37 & 37 & 38 & 39 & 38 & & & & \\
\hline 3.7 & 38 & & 39 & 38 & 35 & 41 & 39 & 37 & & & \\
\hline
\end{tabular}


used in these experiments is 16,784 . Tables II, III, IV, and V show correspondingly the results in percentages for mortality, exogastrulation, other malformations and normal development, respectively.

Death First period (Table II): (a) $\mathrm{CaCl}_{2}$ causes 50 per cent death at $2.8 \times 10^{-2} \mathrm{M}$ and $\mathrm{LiCl}$ at about $1.0 \times 10^{-4} M$. (b) In Table II a line is drawn separating the combinations of $\mathrm{LiCl}$ and $\mathrm{CaCl}_{2}$ which cause more and less than 50 per cent death first period, respectively. (c) Concentrations of $\mathrm{CaCl}_{2}$ from $0.6 \times 10^{-5} \mathrm{M}$ up to concentrations which themselves become noxious exhibit a clear antagonistic action to death caused by $\mathrm{LiCl}$ at various concentrations. At the higher $\mathrm{CaCl}_{2}$ concentrations this action is most pronounced.

Table II. Death first period.

\begin{tabular}{|c|c|c|c|c|c|c|c|c|c|c|c|}
\hline \multirow[b]{2}{*}{$\mathrm{CaCl}_{2}$} & \multirow[b]{2}{*}{0} & \multicolumn{3}{|c|}{$\times 10^{-5} M$} & \multicolumn{3}{|c|}{$\times 10^{-4} M$} & \multicolumn{2}{|c|}{$\times 10^{-3} M$} & \multicolumn{2}{|c|}{$\times 10^{-2} M$} \\
\hline & & 2.4 & 4.8 & 9.6 & 1.9 & 3.8 & 7.7 & 1.5 & 3.1 & 1.2 & 2.5 \\
\hline 0 & $3 \%$ & $7 \%$ & $11 \%$ & $49 \%$ & $67 \%$ & $99 \%$ & $100 \%$ & $100 \%$ & $100 \%$ & $100 \%$ & $100 \%$ \\
\hline $0.6 \times 10^{-5} M$ & 0 & 6 & 18 & 47 & 88 & & & & & & \\
\hline 1.2 & 2 & 9 & 16 & 49 & 85 & & & & & & \\
\hline 2.4 & 2 & 5 & 7 & 11 & 81 & & & & & & \\
\hline 4.8 & 3 & 6 & 8 & 32 & 64 & & & & & & \\
\hline 9.6 & 1 & 6 & 4 & 26 & 78 & & & & & & \\
\hline $1.9 \times 10^{-4} M$ & 3 & 8 & 13 & 6 & 45 & 75 & 98 & 100 & 100 & & \\
\hline 3.8 & 2 & 2 & 10 & 14 & 61 & 87 & 99 & 100 & 100 & & \\
\hline 7.7 & 4 & 5 & 6 & 16 & 41 & 58 & 99 & 100 & 100 & & \\
\hline $1.5 \times 10^{-3} M$ & 4 & 11 & 14 & 15 & 36 & 60 & 95 & 86 & & & \\
\hline 3.1 & 5 & 2 & 6 & 7 & 28 & 45 & 47 & 71 & & & \\
\hline 6.1 & 3 & 4 & 8 & 4 & 12 & 40 & 71 & 74 & & 92 & 100 \\
\hline 9.2 & 0 & & 11 & 7 & 3 & 26 & 87 & 100 & & & \\
\hline $1.2 \times 10^{-2} M$ & 3 & 3 & 11 & 6 & 12 & 24 & 79 & 100 & & & \\
\hline 1.8 & 6 & & 14 & 13 & 13 & 33 & 78 & 86 & & & \\
\hline 2.5 & 31 & 28 & 16 & 17 & 6 & 31 & 79 & 90 & & 100 & 100 \\
\hline 2.8 & 50 & & 18 & 15 & 14 & 31 & 84 & 100 & & & \\
\hline 2.9 & 92 & & 23 & 15 & 6 & 67 & 92 & & & & \\
\hline 3.1 & 69 & & 56 & 40 & 27 & 54 & 86 & 100 & & & \\
\hline 3.2 & 87 & & 32 & 21 & 26 & 78 & 100 & & & & \\
\hline 3.3 & 84 & & 68 & 28 & 31 & 75 & 96 & 100 & & & \\
\hline 3.5 & 92 & & 76 & 38 & 53 & 85 & 100 & & & & \\
\hline 3.7 & 97 & & 69 & 63 & 68 & 90 & 100 & 100 & & & \\
\hline
\end{tabular}


(d) Noxious effects of $\mathrm{CaCl}_{2}$ at higher concentrations are antagonized by $\mathrm{LiCl}$ addition.

For a graphical representation death-rate curves are drawn (as in Fig. 1) by plotting mortality against the logarithm of the concentrations of $\mathrm{LiCl}$ at constant $\mathrm{CaCl}_{2}$ concentrations of $0,0.6 \times 10^{-5} \mathrm{M}, 1.2 \times 10^{-5} \mathrm{M}$ etc. Similarly mortality is plotted against the logarithm of the $\mathrm{CaCl}_{2}$ concentrations at constant $\mathrm{LiCl}$ concentrations of $4.8,9.6,19.0,38.0$ and $77.0 \times 10^{-5} \mathrm{M}$. The concentrations of $\mathrm{LiCl}$ (or $\mathrm{CaCl}_{2}$ ) found at the intersection of the curves and the 50 per cent mortality line provide the 50 per cent death-rate concentration of $\mathrm{LiCl}$ (or $\mathrm{CaCl}_{2}$ ) at a particular $\mathrm{CaCl}_{2}$ (or $\mathrm{LiCl}$ ) concentration.

In all 31 curves can be drawn, which provide 31 concentration combinations for 50 per cent death first period. It seemed useless to publish all the

TABLE III. Exogastrulation.

\begin{tabular}{|c|c|c|c|c|c|c|c|c|c|c|c|}
\hline \multirow[b]{2}{*}{$\mathrm{CaCl}_{2}$} & \multirow[b]{2}{*}{0} & \multicolumn{3}{|c|}{$\times 10^{-5} M$} & \multicolumn{3}{|c|}{$\times 10^{-4} M$} & \multicolumn{2}{|c|}{$\times 10^{-3} M$} & \multicolumn{2}{|c|}{$\times 10^{-2} M$} \\
\hline & & 2.4 & 4.8 & 9.6 & 1.9 & 3.8 & 7.7 & 1.5 & 3.1 & 1.2 & 2.5 \\
\hline 0 & $1 \%$ & $13 \%$ & $82 \%$ & $19 \%$ & $30 \%$ & $1 \%$ & $0 \%$ & $0 \%$ & $0 \%$ & $0 \%$ & $0 \%$ \\
\hline $0.6 \times 10^{-5} M$ & 0 & 29 & 79 & 53 & 3 & & & & & & \\
\hline 1.2 & 0 & 27 & 72 & 43 & 6 & & & & & & \\
\hline 2.4 & 0 & 9 & 73 & 87 & 17 & & & & & & \\
\hline 4.8 & 0 & 13 & 73 & 58 & 23 & & & & & & \\
\hline 9.6 & 1 & 34 & 75 & 55 & 22 & & & & & & \\
\hline $1.9 \times 10^{-4} M$ & 0 & 12 & 66 & 94 & 55 & 20 & 2 & 0 & 0 & & \\
\hline 3.8 & 1 & 2 & 64 & 86 & 31 & 11 & 0 & 0 & 0 & & \\
\hline 7.7 & 0 & 6 & 45 & 82 & 53 & 32 & 1 & 0 & 0 & & \\
\hline $1.5 \times 10^{-3} M$ & 1 & 4 & 47 & 85 & 62 & 17 & 5 & 0 & & & \\
\hline 3.1 & 3 & 10 & 32 & 91 & 66 & 38 & 8 & 6 & & & \\
\hline 6.1 & 4 & 6 & 20 & 91 & 88 & 60 & 18 & 4 & & 8 & 0 \\
\hline 9.2 & 1 & & 13 & 87 & 97 & 12 & 10 & 0 & & & \\
\hline $1.2 \times 10^{-2} M$ & 0 & 0 & 10 & 81 & 88 & 75 & 18 & 0 & & & \\
\hline 1.8 & 0 & & 14 & 76 & 86 & 67 & 20 & 4 & & & \\
\hline 2.5 & 12 & 6 & 17 & 75 & 94 & 69 & 21 & 8 & & 0 & 0 \\
\hline 2.8 & 16 & & 20 & 75 & 86 & 69 & 14 & 0 & & & \\
\hline 2.9 & 0 & & 41 & 85 & 94 & 33 & 8 & & & & \\
\hline 3.1 & 8 & & 25 & 59 & 73 & 46 & 14 & 0 & & & \\
\hline 3.2 & 10 & & 55 & 79 & 74 & 22 & 0 & & & & \\
\hline 3.3 & 10 & & 25 & 72 & 69 & 25 & 4 & 0 & & & \\
\hline 3.5 & 8 & & 24 & 62 & 47 & 15 & 0 & & & & \\
\hline 3.7 & 3 & & 31 & 37 & 29 & 10 & 0 & 0 & & & \\
\hline
\end{tabular}


curves. In Fig. 3 the combinations are plotted in one graph. In this figure the 50 per cent death-rate concentration for each of the two salts separately is taken as the unit $\left(\mathrm{CaCl}_{2} 2.8 \times 10^{-2} \mathrm{M}\right.$, and $\mathrm{LiCl} 10^{-4} \mathrm{M}$, respectively). On the ordinate, concentrations of $\mathrm{CaCl}_{2}$ in the salt mixture are given, expressed as parts and multiples of the " 50 per cent death-rate unit concentration" of $\mathrm{CaCl}_{2}$ in the absence of $\mathrm{LiCl}$. The corresponding concentrations in moles are found on the right side of the figure. On the abscissae, the concentrations of $\mathrm{LiCl}$ are given as parts and multiples of the " 50 per cent death-rate unit concentration" of LiCl alone.

A smooth line is drawn through the estimated points of concentration combinations which cause 50 per cent death. This line is called the "isothanate for 50 per cent mortality first period" (isothanate 50).

TABLE IV. Other malformations.

\begin{tabular}{|c|c|c|c|c|c|c|c|c|c|c|c|}
\hline \multirow[b]{2}{*}{$\mathrm{CaCl}_{2}$} & \multirow[b]{2}{*}{0} & \multicolumn{3}{|c|}{$\times 10^{-5} M$} & \multicolumn{3}{|c|}{$\times 10^{-4} M$} & \multicolumn{2}{|c|}{$\times 10^{-3} M$} & \multicolumn{2}{|c|}{$\times 10^{-2} M$} \\
\hline & & 2.4 & 4.8 & 9.6 & 1.9 & 3.8 & 7.7 & 1.5 & 3.1 & 1.2 & 2.5 \\
\hline 0 & $2 \%$ & $29(15) \%$ & $5(1) \%$ & $2 \%$ & $3 \%$ & $0 \%$ & $0 \%$ & $0 \%$ & $0 \%$ & $0 \%$ & $0 \%$ \\
\hline $0.6 \times 10^{-5} M$ & 0 & $27(21)$ & 3 & 0 & 9 & & & & & & \\
\hline 1.2 & 0 & 39 (15) & 12 & 8 & 9 & & & & & & \\
\hline 2.4 & 0 & $21(16)$ & $10(4)$ & 2 & 2 & & & & & & \\
\hline 4.8 & 3 & $23(10)$ & $13(8)$ & 10 & 13 & & & & & & \\
\hline 9.6 & 14 & $18(11)$ & $8(1)$ & 19 & 0 & & & & & & \\
\hline $1.9 \times 10^{-4} M$ & 2 & $16(8)$ & $16(6)$ & 0 & 0 & 8 & 0 & 0 & 0 & & \\
\hline 3.8 & 1 & $23(15)$ & $24(6)$ & 0 & 13 & 3 & 1 & 0 & 0 & & \\
\hline 7.7 & 2 & $13(10)$ & $36(9)$ & 2 & 6 & 10 & 0 & 0 & 0 & & \\
\hline $1.5 \times 10^{-3} M$ & 0 & $13(11)$ & $28(7)$ & 0 & 2 & 23 & 0 & 14 & & & \\
\hline 3.1 & 2 & 0 & $20(9)$ & 2 & 2 & 14 & 45 & 23 & & & \\
\hline 6.1 & 0 & $10(8)$ & $32(16)$ & 4 & 0 & 0 & 0 & 0 & 0 & 0 & \\
\hline 9.2 & 1 & & $45(12)$ & 6 & 0 & 2 & 3 & & & & \\
\hline $1.2 \times 10^{-2} M$ & 1 & 0 & $29(9)$ & $12(3)$ & 0 & 1 & 3 & 0 & & & \\
\hline 1.8 & 5 & & $22(6)$ & 10 & 1 & 0 & 2 & 0 & & & \\
\hline 2.5 & 7 & $51(24)$ & $32(10)$ & $6(1)$ & 0 & 0 & 0 & 2 & & & \\
\hline 2.8 & 4 & & $46(12)$ & $10(1)$ & 0 & 0 & 2 & 0 & & & \\
\hline 2.9 & 5 & & $15(2)$ & 0 & 0 & 0 & 0 & & & & \\
\hline 3.1 & 18 & & 18 & 1 & 0 & 0 & 0 & 0 & & & \\
\hline 3.2 & 3 & & 3 & 0 & 0 & 0 & 0 & & & & \\
\hline 3.3 & 2 & & 5 & 0 & 0 & 0 & 0 & 0 & & & \\
\hline 3.5 & 0 & & 0 & 0 & 0 & 0 & 0 & & & & \\
\hline 3.7 & 0 & & 0 & 0 & 3 & 0 & 0 & 0 & & & \\
\hline
\end{tabular}


Fig. 3 shows that the $\mathrm{CaCl}_{2}$ concentration needed to cause 50 per cent death of the egg cells in the presence of low $\mathrm{LiCl}$ concentrations is about 1.3 times higher than in the experiments with $\mathrm{CaCl}_{2}$ alone.

Reciprocally, the $\mathrm{LiCl}$ concentrations needed to cause 50 per cent death increase up to 5 times with increasing $\mathrm{CaCl}_{2}$ concentrations.

Exogastrulation (Table III): The results of all experiments are compiled in Table III. Exogastrulae may occur in high percentages after treatment with $\mathrm{LiCl}$. The effective range of concentrations corresponds to that for death first period. Exogastrulation reaches a maximum at about $4.8 \times 10^{-5} \mathrm{M}$, then it decreases with concomitant increase of "death first period". After a treatment with $\mathrm{CaCl}_{2}$ alone small percentages of exogastrulae may be found. It is obvious from Table III that addition of $\mathrm{CaCl}_{2}$ greatly reduces the numbers

TABLE V. Normal development.

\begin{tabular}{|c|c|c|c|c|c|c|c|c|c|c|c|}
\hline \multirow[b]{2}{*}{$\mathrm{CaCl}_{2}$} & \multirow[b]{2}{*}{0} & \multicolumn{3}{|c|}{$\times 10^{-5} M$} & \multicolumn{3}{|c|}{$\times 10^{-4} M$} & \multicolumn{2}{|c|}{$\times 10^{-3} M$} & \multicolumn{2}{|c|}{$\times 10^{-2} M$} \\
\hline & & 2.4 & 4.8 & 9.6 & 1.9 & 3.8 & 7.7 & 1.5 & 3.1 & 1.2 & 2.5 \\
\hline 0 & $94 \%$ & $21 \%$ & $2 \%$ & - & - & - & - & - & - & - & - \\
\hline $0.6 \times 10^{-5} M$ & 100 & 38 & - & - & - & - & - & - & - & - & - \\
\hline 1.2 & 98 & 25 & - & - & - & & & & & & \\
\hline 2.4 & 98 & 65 & 10 & - & - & & & & & & \\
\hline 4.8 & 94 & 58 & 6 & - & - & & & & & & \\
\hline 9.6 & 84 & 42 & 13 & & & & & & & & \\
\hline $1.9 \times 10^{-4} M$ & 95 & 64 & 5 & - & - & - & -- & - & - & & \\
\hline 3.8 & 96 & 73 & 2 & - & - & - & - & - & - & & \\
\hline 7.7 & 94 & 76 & 13 & - & - & - & - & - & - & & \\
\hline $1.5 \times 10^{-3} M$ & 95 & 72 & 11 & - & - & - & - & - & & & \\
\hline 3.1 & 90 & 88 & 42 & -- & 4 & 3 & - & - & & & \\
\hline 6.1 & 93 & 80 & 40 & 1 & - & - & - & - & & $\ldots$ & - \\
\hline 9.2 & 98 & & 31 & - & - & - & - & 一 & & & \\
\hline $1.2 \times 10^{-2} M$ & 96 & 97 & 50 & 1 & - & - & - & - & & & \\
\hline 1.8 & 89 & & 50 & 1 & - & - & - & - & & & \\
\hline 2.5 & 50 & 15 & 35 & 2 & - & - & - & - & & - & - \\
\hline 2.8 & 30 & & 16 & - & - & - & - & - & & & \\
\hline 2.9 & 3 & & 21 & -- & - & - & $\ldots$ & & & & \\
\hline 3.1 & 5 & & 1 & - & $-\ldots$ & - & - & - & & & \\
\hline 3.2 & - & & 10 & - & - & - & - & & & & \\
\hline 3.3 & 4 & & 2 & - & - & - & - & -- & & & \\
\hline 3.5 & - & & - & - & $\ldots$ & - & - & & & & \\
\hline 3.7 & - & & - & - & - & - & - & - & & & \\
\hline
\end{tabular}


of exogastrulae caused by $\mathrm{LiCl}$ concentrations 2.4 and $4.8 \times 10^{-5} \mathrm{M}$. Comparison with Table $\mathrm{V}$ shows that simultaneously the number of normally developing eggs increases.

Addition of $\mathrm{CaCl}_{2}$ in experiments with $\mathrm{LiCl} 9.6 \times 10^{-5} \mathrm{M}$ causes an increase in the number of exogastrulae with increasing $\mathrm{CaCl}_{2}$ concentrations, whereas normal development hardly increases (Table V). Comparison with Table II shows that simultaneously the death rate decreases. The same effect of $\mathrm{CaCl}_{2}$ is observed with the $\mathrm{LiCl}$ concentrations $1.9,3.8$ and $7.7 \times 10^{-4} M$. At $\mathrm{CaCl}_{2}$ concentrations which cause a death rate above 50 per cent addition of $\mathrm{LiCl}$ causes a decrease in death rate with a concomitant rise in exogastrulation.

Fig. 3 shows in which region of concentration combinations more than 50 per cent exogastrulation is found, namely, within the lightly shaded area enclosed by the isothanate 50 .

Normal nevelopmfat ( $\mathrm{T}_{\mathrm{able}} \mathrm{V}$ ): From Table $\mathrm{V}$ and the darkly shaded area in Fig. 3 it is seen that addition of $\mathrm{CaCl}_{2}$ promotes normal development of eggs which would otherwise exogastrulate by the action of LiCl.

Other malformations (TABLE IV): Under this heading are comprised all head malformations, shell malformations, unspecific malformations and death second period. The percentages of head malformations are given in brackets in Table IV. The numbers of shell malformations and death second period were very small in these experiments.

As can be seen from Table IV, unspecific malformations and head malformations occur primarily at the $\mathrm{LiCl}$ concentrations 2.4 and $4.8 \times 10^{-5} \mathrm{M}$. Addition of $\mathrm{CaCl}_{2}$ in experiments with $\mathrm{LiCl} 2.4 \times 10^{-5} \mathrm{M}$ causes a decrease in the number of "other malformations" with a concomitant increase in normal development and a decrease in exogastrulation. In experiments with $\mathrm{LiCl}$ $4.8 \times 10^{-5} \mathrm{M}$ non-noxious $\mathrm{CaCl}_{2}$ concentrations cause an increase in the number of "other malformations" concomitantly with an increase in normal development and a decrease in exogastrulation.

In Fig. 3 the "unshaded" area shows the region of concentration combinations in which primarily "other malformations" occur.

Conclusions: (1) With regard to "death first period" a reciprocal antagonism of $\mathrm{CaCl}_{2}$ and $\mathrm{LiCl}$ is observed; (2) At lower $\mathrm{LiCl}$ concentrations (2.4 and $4.8 \times 10^{-5} \mathrm{M}$ ) addition of $\mathrm{CaCl}_{2}$ promotes normal development of otherwise exogastrulating embryos; (3) At higher LiCl concentrations addition of $\mathrm{CaCl}_{2}$ protects the eggs against death but instead they develop into exogastrulae; (4) "Death first period" caused by $\mathrm{CaCl}_{2}$ in high concentrations decreases by addition of LiCl. Instead the number of exogastrulae increases markedly, whereas the number of normal embryos increases only slightly. 
The interaction of $\mathrm{CaCl}_{2}$ and $\mathrm{NaCl}$.- The interaction of $\mathrm{CaCl}_{2}$ and $\mathrm{NaCl}$ has been studied in the same way as the $\mathrm{CaCl}_{2}-\mathrm{LiCl}$ interaction.

The results are summarized in Fig. 4, the isothanate 50 for the $\mathrm{NaCl}-$ $\mathrm{CaCl}_{2}$ interaction, being derived in the same way as the isothanate 50 for $\mathrm{LiCl}$ and $\mathrm{CaCl}_{2}$.

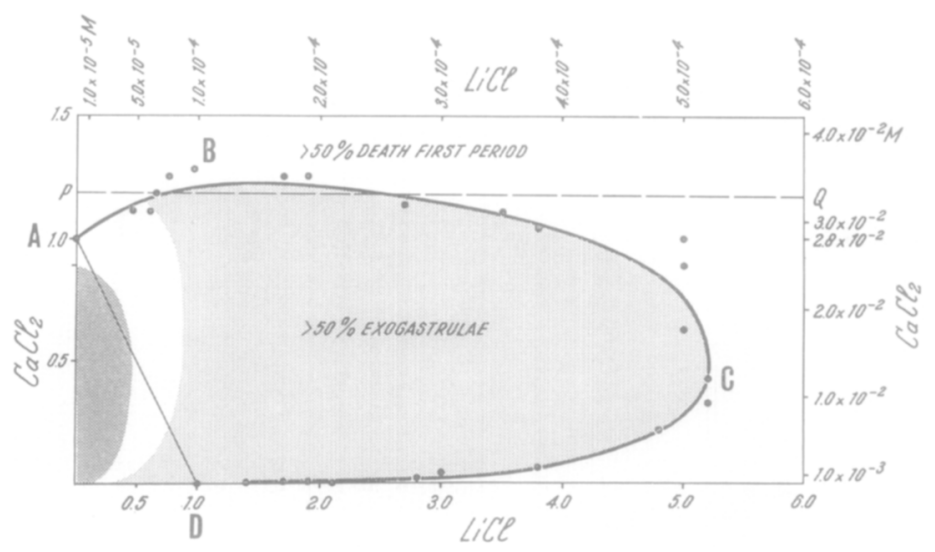

Fig. 3.- Interaction of $\mathrm{CaCl}_{2}$ and $\mathrm{LiCl}$ with regard to 50 per cent death fïrst period.

Ordinates: concentrations of $\mathrm{CaCl}_{2}$ in the treatment solutions expressed as parts or multiples of the 50 per cent death rate conc. of $\mathrm{CaCl}_{2}$ alone. At the right side the corresponding concentrations in moles are given.

Abscissae: concentrations of $\mathrm{LiCl}$ in the same manner as for $\mathrm{CaCl}_{\mathbf{2}}$.

The dots indicate the determined concentration combinations which cause 50 per cent death. The concentration combinations within the area of the curve A-B-C-D (the isothanate 50) cause less than 50 per cent death first period. Outside this area the death rate is higher than 50 per cent.

The lighlty shaded area within the area enclosed by the isothanate 50 indicates which concentration combinations cause more than 50 per cent exogastrulae and the darkly shaded area the same for normal development. The "other malformations" are mostly found in the unshaded arca between the two. The line $\mathbf{A - D}$ would have been found as the isothanate 50 in the case of additivity of $\mathrm{CaCl}_{2}$ and $\mathrm{LiCl}$ effects.

The line $\mathrm{P}-\mathrm{Q}$ connects the $\mathrm{CaCl}+\mathrm{LiCl}$ combinations with an osmotic value comparable with $10^{-1} M$ saccharose.

For the sake of brevity the publication of all figures is omitted. The total number of eggs used in these experiments is 13,189 .

DeATH FIRST PERIOD: $(a) \mathrm{NaCl}$ causes 50 per cent mortality at a concentration of $1.8 \times 10^{-2} M$, and $\mathrm{CaCl}_{2}$ at a concentration of $2.8 \times 10^{-2} M$ (the unit concentrations); (b) Addition of $\mathrm{NaCl}$ in small amounts (from $10^{-5} M$ to $\left.2 \times 10^{-3} M\right)$ to a $\mathrm{CaCl}_{2}$ solution which causes 50 per cent death means that the $\mathrm{CaCl}_{2}$ concentration has to be raised in order to obtain 50 per cent death again. The maximum lies around $\mathrm{CaCl}_{2} 3.5 \times 10^{-2} \mathrm{M}(1.25 \times$ unit $)$ and $\mathrm{NaCl}$ $2 \times 10{ }^{3} M\left(0.11 \times\right.$ unit). (c) Addition of $\mathrm{CaCl}_{2}$ in small amounts (from $10^{-5} \mathrm{M}$ 
to $\pm 10^{-3} M$ ) to a solution of $\mathrm{NaCl}$ which causes 50 per cent death means that the $\mathrm{NaCl}$ concentration has to be raised in order to obtain 50 per cent death again. The maximum is found at about $5 \times 10^{-2} \mathrm{M} \mathrm{NaCl}(2.75 \times$ unit $)$ and about $10^{-3} \mathrm{M} \mathrm{CaCl}(0.035 \times$ unit). (d) Between these maxima (see $(b)$ and $(c)$ ) increasing $\mathrm{CaCl}_{2}$ concentrations go hand in hand with decreasing $\mathrm{NaCl}$ concentrations and inversely.

Exogastrulation: Both $\mathrm{CaCl}_{2}$ and $\mathrm{NaCl}$ provoke exogastrulae in small numbers only. The light shading along the isothanate 50 in Fig. 4 indicates the concentration regions where more than 5 per cent exogastrulae occur.

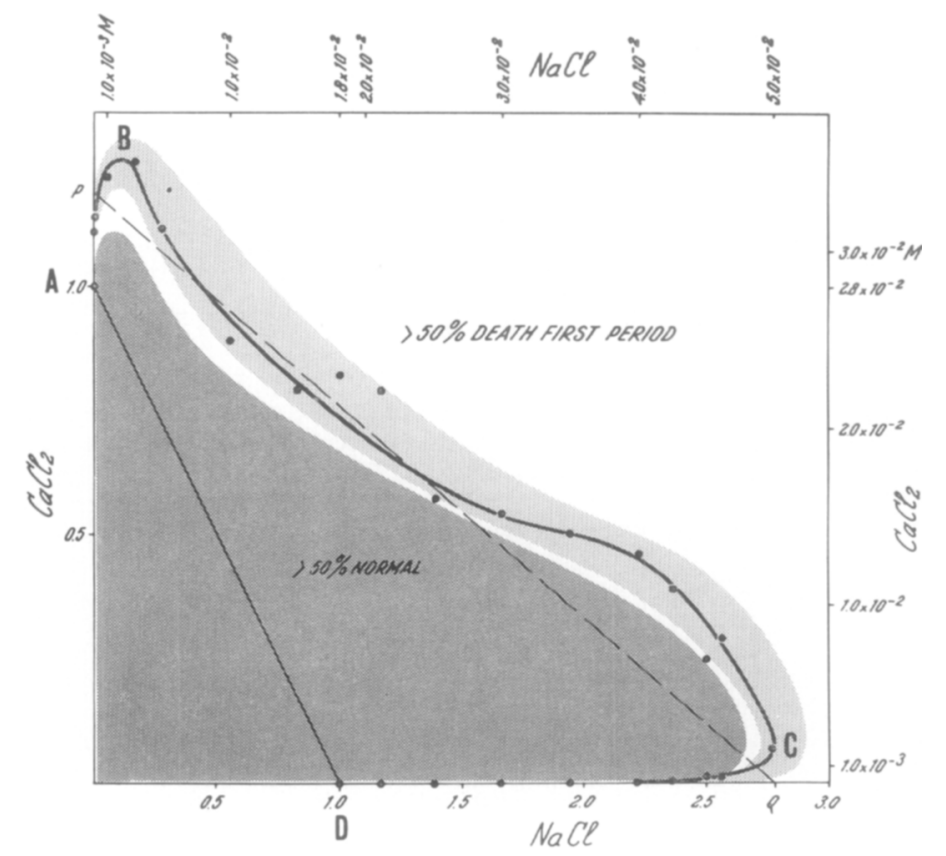

Fig. 4.-Interaction of $\mathrm{CaCl}_{2}$ and $\mathrm{NaCl}$ with regard to 50 per cent death first period.

Ordinates: concentrations of $\mathrm{CaCl}_{2}$ in the treatment solutions expressed as parts or multiples of the 50 per cent death rate conc. of $\mathrm{CaCl}_{2}$ alone. At the right side the corresponding concentrations in moles are given. Abscissae: concentrations of $\mathrm{NaCl}$ in the same manner as for $\mathrm{CaCl}_{2}$.

The dots indicate the determined concentration combinations which cause 50 per cent death. The concentration combinations within the area of the curve A-B-C-D (the isothanate 50) cause less than 50 per cent death first period. Outside this area the death rate is higher than 50 per cent.

The lightly shaded zone along the isothanate 50 indicates concentrations which cause more than 5 per cent exogastrulae. The darkly shaded area indicates the concentration combinations which allow more than 50 per cent normal development. The "other malformations" are mostly found in the unshaded area between the two.

The line A-D would have been found as the isothanate 50 in the case of additivity of $\mathrm{Cacl}_{2}$ and $\mathrm{NaCl}$ effects.

The line $\mathrm{P}-\mathrm{Q}$ connects the $\mathrm{CaCl}_{2}+\mathrm{NaCl}$ combinations of an osmotic value comparable with $10^{-1} M$ saccharose. 
Normal development: In Fig. 4 the shaded area encloses the concentration combinations of $\mathrm{CaCl}_{2}$ and $\mathrm{NaCl}$ which give more than 50 per cent normal development. It is obvious that the reciprocal antagonism found for mortality is paralleled in the case of normal development. Addition of $\mathrm{CaCl}_{2}$ in a $\mathrm{NaCl}$ treatment and, conversely, addition of $\mathrm{NaCl}$ to noxious $\mathrm{CaCl}_{2}$ concentrations furthers normal development.

Other malformations: Other malformations occur only in small numbers. The "unshaded" area in Fig. 4 between normal development and exogastrulation indicates the region of concentration combinations which cause other malformations preferably.

Conclusions: $(a) \mathrm{NaCl}$ antagonizes the $\mathrm{CaCl}_{2}$ effect, as shown by the ascending line of 50 per cent death starting at $\mathrm{CaCl}_{2}$ in unit concentration with a maximum at $\mathrm{CaCl}_{2} 1.25 \times$ unit. The decrease of death first period by $\mathrm{NaCl}$ antagonism is paralleled by an increase in normal development. (b) $\mathrm{CaCl}_{2}$ antagonizes the $\mathrm{NaCl}$ effect, causing an increase in $\mathrm{NaCl}$ concentration for 50 per cent death from 1.00 up to about $2.75 \times$ unit. Again decreasing death rate is paralleled by increasing normal development.

The interaction of $\mathrm{CaCl}_{2}$ and $\mathrm{KCl}$.- The interaction of $\mathrm{CaCl}_{2}$ and $\mathrm{KCl}$ has been studied in the same way as the interaction with $\mathrm{LiCl}$ and $\mathrm{NaCl}$.

Fig. 5 shows the results. The total number of eggs used in these experiments is 9854 .

DeATH FIRST PERIOD: $(a) \mathrm{KCl}$ causes 50 per cent mortality at a concentration of $5.9 \times 10^{-4} \mathrm{M}$, and $\mathrm{CaCl}_{2}$ at a concentration of $2.9 \times 10^{-2} \mathrm{M}$ (the unit concentrations). (b) As for $\mathrm{NaCl}$ and $\mathrm{LiCl}$, addition of $\mathrm{KCl}$ in small amounts (from $4 \times 10^{-4} M$ up to $3 \times 10^{-3} M$ ) antagonizes the noxious effects of $\mathrm{CaCl}_{2}$. The maximum of this interaction lies at a $\mathrm{CaCl}_{2}$ concentration of about $4.3 \times 10^{-2} M( \pm 1.50 \times$ unit $)$ with $\mathrm{KCl} 3 \times 10^{-3} M(5.00 \times$ unit $)$. (c) Similarly addition of $\mathrm{CaCl}_{2}$ (from $2 \times 10^{-1}$ to $2 \times 10^{-2} \mathrm{M}$ ) antagonizes death caused by KCl. The maximum of this interaction lies at a $\mathrm{KCl}$ concentration of about $2.7 \times 10^{-2} M(45.00 \times$ unit $)$ and $\mathrm{CaCl}_{2} 2 \times 10^{-2} M(0.69 \times$ unit $)$.

Exogastrilation: $\mathrm{KCl}$ causes exogastrulae in small percentages only. In the combination experiments exogastrulae occurred in small numbers again in the area of increasing death rates (Fig. 5, concentration combinations along the isothanate 50 indicated by the light shading).

Normal development: The interaction of $\mathrm{CaCl}_{2}$ and $\mathrm{KCl}$ with regard to normal development again mirrors the antagonism pattern found for mortality. The darkly shaded area in Fig. 5 indicates the region of more than 50 per cent normal development. 
OTHER MALFORMATIONS: Other malformations occur only in small numbers. The "unshaded" area in Fig. 5 between normal development and exogastrulation indicates the region of concentration combinations which cause other malformations preferahly.

Conclusions: (a) $\mathrm{KCl}$ antagonizes the $\mathrm{CaCl}_{2}$ effect, as shown by the as-

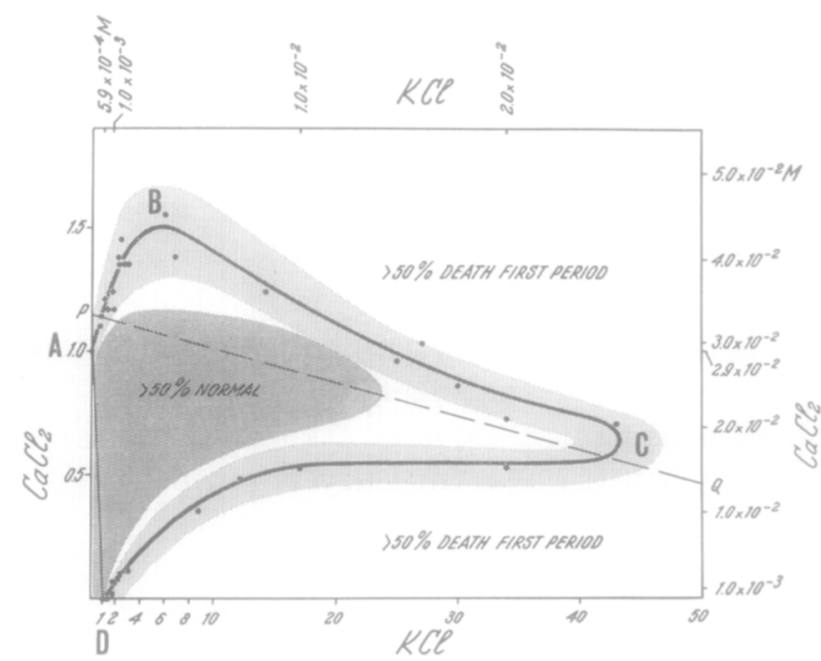

Fig. 5.-Interaction of $\mathrm{CaCl}_{2}$ and $\mathrm{KCl}$ with regard to 50 per cent death first period. For the explanation, see legend to Fig. 4 , in which, instead of $\mathrm{NaCl}, \mathrm{KCl}$ is to be read.

cending line of 50 per cent death starting at $\mathrm{CaCl}_{2}$ in unit concentration with a maximum at $\mathrm{CaCl}_{2} 1.5 \times$ unit. The decrease of death first period by $\mathrm{KCl}$ antagonism is paralleled by an increase in normal development. (b) $\mathrm{CaCl}_{2}$ antagonizes the $\mathrm{KCl}$ effect, causing an increase in $\mathrm{KCl}$ concentration for 50 per cent death from 1.00 up to $45.00 \times$ unit. Again decreasing death rate is paralleled by increasing normal development.

The interaction of $\mathrm{CaCl}_{2}$ and $\mathrm{CsCl}$.--The interaction of $\mathrm{CaCl}_{2}$ and $\mathrm{CsCl}$ has been studied as described for the other ions. In these experiments 50 per cent death is found for $\mathrm{CaCl}_{2}$ at $2.7 \times 10^{-2} \mathrm{M}$ and for $\mathrm{CsCl}$ at $9 \times 10^{-5} \mathrm{M}$ (the unit concentrations). Fig. 6 shows the results. The total number of eggs used in these experiments is 11,682 .

DEATH FIRST PERIOD: $(a)$ With $\mathrm{CsCl}$ it is also observed that after addition of small amounts of the salt $\left(1.5 \times 10^{-5} M-3.6 \times 10^{-4} M\right)$ the $\mathrm{CaCl}_{2}$ concentration must be raised to obtain 50 per cent death. The maximum of this inter- 
action is found with about $3.4 \times 10^{-2} \mathrm{M} \mathrm{CaCl}_{2}(1.26 \times$ unit and up to $3.6 \times$ $10^{-4} \mathrm{M} \mathrm{CsCl}\left(4.00 \times\right.$ unit). (b) Addition of $\mathrm{CaCl}_{2}$ (from $1.35 \times 10^{-3} \mathrm{M}$ to $1.9 \times$ $10^{-2} M$ ) antagonizes death caused by $\mathrm{CsCl}$. The maximum of this interaction lies at a $\mathrm{CsCl}$ concentration of about $10^{-3} \mathrm{M}(11.00 \times$ unit $)$ and $1.9 \times 10^{-2} \mathrm{M}$ $\mathrm{CaCl}_{2}(0.70 \times$ unit $)$.

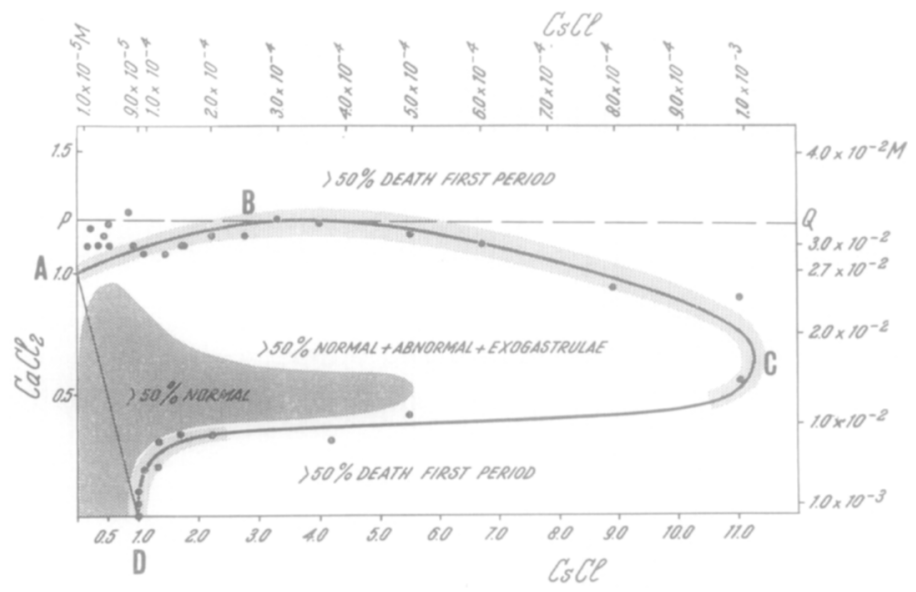

Fig. 6.-Interaction of $\mathrm{CaCl}_{2}$ and $\mathrm{CsCl}$ with regard to 50 per cent death first period. For the explanation, see legend to Fig. 4, in which, instead of $\mathrm{NaCl}, \mathrm{CsCl}$ is to be read.

Exogastrulation: CsCl causes exogastrulae only in small percentages. In the combination experiments with $\mathrm{CaCl}_{2}$ cxogastrulae occur in small numbers, linked to an increasing death rate. The light shading along the isothanate 50 indicates at which concentrations they are found. The shading is interrupted over part of the 50 per cent death-rate line. For this area no data were available.

Normal development: The interaction of $\mathrm{CaCl}_{2}$ and $\mathrm{CsCl}$ with regard to normal development parallels the antagonism pattern found for mortality. The darkly shaded area in Fig. 6 indicates the region of more than 50 per cent normal development.

Othl: MALFORMATIONS: Other malformations occur only in small numbers. The "unshaded" area in Fig. 6 between normal development and exogastrulation indicates the region of concentration combinations which causes other malformations preferably.

Conclusions: (a) $\mathrm{CsCl}$ antagonizes the $\mathrm{CaCl}_{2}$ effect, as shown by the ascending line of 50 per cent death, starting at $\mathrm{CaCl}_{2}$ in unit concentration with a maximum at $\mathrm{CaCl}_{2} 1.26 \times$ unit. The decrease of dealh first period by $\mathrm{CsCl}$ 
antagonism is paralleled with an increase in normal development. (b) $\mathrm{CaCl}_{2}$ antagonizes the $\mathrm{CsCl}$ effect, causing an increase in $\mathrm{CsCl}$ concentration for 50 per cent death from 1.00 up to $11.00 \times$ unit. Again decreasing death rate is paralleled by increasing normal development.

\section{General conclusions}

(1) Alkali chlorides antagonize death caused by $\mathrm{CaCl}_{2}$. With $\mathrm{NaCl}, \mathrm{KCl}$ and $\mathrm{CsCl}$ the number of normally developing embryos increases; with $\mathrm{LiCl}$ normal development is promoted only to a small extent, but instead many exogastrulae are found.

(2) $\mathrm{CaCl}_{2}$ antagonizes death caused by alkali chlorides. The number of normally developing embryos increases in all cases.

(3) The reciprocal antagonism between $\mathrm{CaCl}_{2}$, on the one hand, and $\mathrm{LiCl}$, $\mathrm{NaCl}, \mathrm{KCl}$ and $\mathrm{CsCl}$, respectively, on the other, with regard to normal and abnormal development or death, gives rise to similar isothanates 50 .

\section{DISCUSSION}

Analysis of the isothanates 50.-The shape of all curves (Figs. 3-6) is similar. Starting at the unit concentration for $\mathrm{CaCl}_{2}$, after addition of nonnoxious alkali chloride concentrations, the $\mathrm{CaCl}_{2}$ concentrations needed to reach 50 per cent death are higher than in experiments with $\mathrm{CaCl}_{2}$ alone (part A-B). At B a maximum is reached. Starting at the unit point for an alkali chloride, addition of $\mathrm{CaCl}_{2}$ goes together with increased alkali chloride concentrations (part $\mathrm{C}-\mathrm{D}$ ). At $\mathrm{C}$ again a maximum is reached.

All curves (Figs. 3-6) are provided with a straight line connecting the unit effect points $A$ and $D$ on the two axes. This line would have been found as the isothanate 50 in the case of additivity of the effects of the separate cations.

The deviations in the direction of higher $\mathrm{CaCl}_{2}$ concentrations after addition of alkali chlorides (part A-B) are of the same order in all cases. This can be read from Figs. 3-6, and is also demonstrated in Fig. 7, in which the effective $\mathrm{CaCl}_{2}$ concentrations are plotted logarithmically against the added alkali chloride concentrations.

The rise of the $\mathrm{CaCl}_{2}$ concentrations is rather small, and of the order of $0.30-0.40 \times$ unit. That no further rise of the $\mathrm{CaCl}_{2}$ concentrations is found can readily be explained by the fact that $\mathrm{CaCl}_{2}$ concentrations above $3.3 \times$ $10^{-2} M$ have an osmotic effect which is noxious to the egg cell. It has been observed that $0.093 \mathrm{M}$ concentrations of sucrose and urea prevent the normal swelling of Limnaea eggs [10]. Experiments with sucrose according to 
the standard procedure have shown that treatment with $9 \times 10^{-2} M$ has hardly any noxious effect; 50 per cent mortality is found at $1.1 \times 10^{-1} \mathrm{M}$, and over 70 per cent mortality at $1.25 \times 10^{-1} M$ (unpublished observations). İn order to show the relation between the isothanate 50 and the osmotic value of the treatment solutions, in Figs. 3-6 and Fig. 7, a line P--Q is drawn which con-

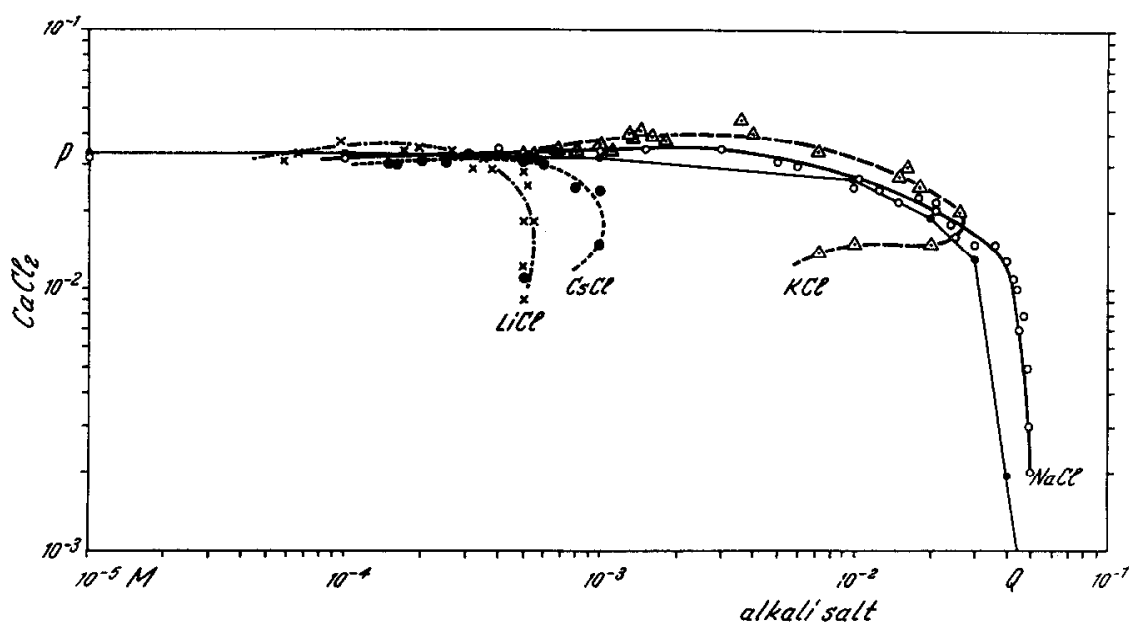

Fig. 7.-Effect of addition of $\mathrm{LiCl}, \mathrm{CsCl}, \mathrm{KCl}$ and $\mathrm{NaCl}$ with regard to the $\mathrm{CaCl}_{2}$ concentrations which cause 50 per cent death first period.

Ordinates: logarithm of the $\mathrm{CaCl}_{2}$ concentrations in moles. Without addition of alkali salts the $\mathrm{CaCl}_{2}$ concentration which causes 50 per cent death first period is about $2.8 \times 10^{-2} \mathrm{M}$.

Abscissae: logarithm of the concentrations of alkali salt in moles.

nects the concentration combinations with an osmotic value equal to $10^{-1} \mathrm{M}$ sucrose. The position of this line with respect to the isothanates 50 explains the maximum of the antagonistic effects of small amounts of alkali chlorides on a $\mathrm{CaCl}_{2}$ treatment. Furthermore it explains the shape of the curves between $\mathrm{B}$ and $\mathrm{C}$, for $\mathrm{NaCl}$ and $\mathrm{KCl}$ and to a lesser extent for $\mathrm{CsCl}$ and $\mathrm{LiCl}$, which apparently is determined by the osmotic value of the treatment solution.

In Fig. 7 it is seen that the concentrations at which the isothanates 50 turn off from the isosmotic line are very different: viz. LiCl between 3 and $5 \times$ $10^{-4} \mathrm{M}$; $\mathrm{CsCl}$ between 4 and $8 \times 10^{-4} \mathrm{M}$; $\mathrm{KCl}$ between 2 and $3 \times 10^{-2} \mathrm{M}$, and $\mathrm{NaCl}$ between 4.5 and $5 \times 10^{-2} \mathrm{M}$. Hence, the sequence $\mathrm{Li}<\mathrm{Cs}<\mathrm{K}<\mathrm{Na}$ is found.

Part $\mathrm{D}-\mathrm{C}$ in the curves (Figs. 3-6) shows the deviations from additivity for the addition of non-noxious amounts of $\mathrm{CaCl}_{2}$ to solutions of alkali chlo- 
rides. Although the shape of this part of the isothanates 50 is similar in all cases, considerable differences are observed between the alkali chlorides.

First of all, 50 per cent death first period without addition of $\mathrm{CaCl}_{2}$ is found at very different concentrations: $\mathrm{TiCl} \sim 10^{-4} \mathrm{M}, \mathrm{CsCl} \sim 9 \times 10^{-5} \mathrm{M}$, $\mathrm{KCl} \sim 5.9 \times 10^{-4} M$ and $\mathrm{NaCl} \sim 1.8 \times 10^{-2} M$. Secondly, the absolute concentration reached at $\mathrm{C}$ differs considerably from salt to salt as do the corresponding $\mathrm{CaCl}_{2}$ concentrations:

$\mathrm{NaCl} 5 \times 10^{-2} \mathrm{M}$ and $\mathrm{CaCl}_{2} 1.4-2.8 \times 10^{-3} \mathrm{M}$

$\mathrm{KCl} 2.5 \times 10^{-2} \mathrm{M}$ and $\mathrm{CaCl}_{2} 1.7-2 \times 10^{-2} \mathrm{M}$

$\mathrm{CsCl} 10^{-3} \mathrm{M}$ and $\mathrm{CaCl}_{2} 1.35-2.5 \times 10^{-2} \mathrm{M}$

$\mathrm{LiCl} 5 \times 10^{-4} \mathrm{M}$ and $\mathrm{CaCl}_{2} 8.5 \times 10^{-3}-2.5 \times 10^{-2} \mathrm{M}$.

With regard to the alkali chlorides the series $\mathrm{Li}<\mathrm{Cs}<\mathrm{K}<\mathrm{Na}$ is found once more. The lower $\mathrm{CaCl}_{2}$ concentrations corresponding with the maximum alkali chloride concentrations, however, show a different sequence: [Ca] $\mathrm{NaCl}<[\mathrm{Ca}] \mathrm{LiCl}<[\mathrm{Ca}] \mathrm{CsCl}<[\mathrm{Ca}] \mathrm{KCl}$. The maximum for $\mathrm{NaCl}$ and to a lesser extent also for $\mathrm{KCl}$ is apparently determined by the osmotic value of the treatment solution. This is clearly not the case for $\mathrm{LiCl}$ and $\mathrm{CsCl}$. An explanation of these effects will be given in the next paragraph.

Chemical interpretation of the isothanates 50.- $\mathrm{CaCl}_{2}$ EFFECTS AND THE INFLUENCE OF ADDITION OF ALKaLI CHLORIDES (PART A-B). In the introduction a hypothesis has been given for the action of $\mathrm{Ca}^{2+}$ ions on egg cells. It was assumed that fixation of too many $\mathrm{Ca}^{2+}$ ions onto phosphate colloids may impair the structure or function of the cell membrane. With regard to the fixation of ions, this hypothesis is based on similarities between the effects of salts on phosphate colloids, in which reversal of charge is used as a criterion $\lfloor 1\rfloor$ and the effects of these salts on egg cells, in which death before gastrulation is used as a criterion [4]. As a further test it was proposed to study the interaction of $\mathrm{CaCl}_{2}$ and alkali chlorides.

Bungenberg de Jong et al. [1] found that, if reversal of charge of phosphate colloids is determined for $\mathrm{CaCl}_{2}$, first without an added second salt and then in the presence of some constant low-alkali salt concentration, it is invariably found that in the latter case the $\mathrm{CaCl}_{2}$ concentration needed to reach the reversal of charge point is higher than in the experiment with $\mathrm{CaCl}_{2}$ alone. Bungenberg de Jong et al. [1] proved that the effect was due to the addition of anions through lowering of the activity coefficient of calcium.

In our experiments the interaction of $\mathrm{LiCl}, \mathrm{NaCl}, \mathrm{KCl}$ and $\mathrm{CsCl}$ with $\mathrm{CaCl}_{2}$ in noxious concentrations is studied. It is found that equal amounts of these salts have similar effects on the mortality caused by $\mathrm{CaCl}_{2}$ (part $\mathrm{A}-\mathrm{B}$ ) (Figs. 
3-6, Fig. 7). Increased $\mathrm{CaCl}_{2}$ concentrations have to be applied in order to obtain the same mortality.

In the in vitro experiments of Bungenberg de Jong et al. [1] it was also found that with increasing alkali salt concentrations a point is reached beyond which no further increase of the reversal of charge concentration of $\mathrm{CaCl}_{2}$ oc-

Fig. 8.-Reversal of charge of alcohol-soluble soya bean phosphatide, with mixtures of $\mathrm{CaCl}_{2}+\mathrm{NaCl}$.

Ordinates: concentration of $\mathrm{CaCl}_{2}$ in the salt mixture expressed as percentage of the reversal of charge concentration of $\mathrm{CaCl}_{2}$ in the absence of NaCI.

Abscissae: concentration of $\mathrm{NaCl}$ in the salt mixlure expressed as percentage of the reversal of charge concentration of $\mathrm{NaCl}$ in the absence of another salt. (After H. G. Bungenberg de Jong et al.)

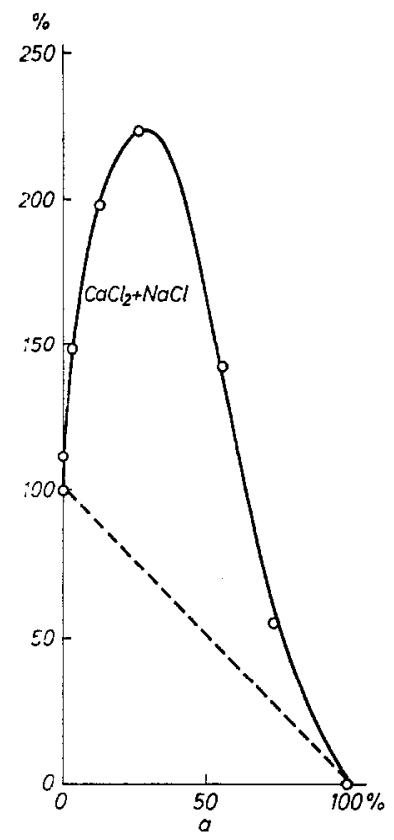

curs (Fig. 8). This was explained by the fact that above this concentration a fixation of alkali metal ions on the colloid occurs. Furthermore it was observed that the height of the antagonism curves varied with the reversal of charge concentrations of the different alkali ions in comparison with the reversal of charge concentration of $\mathrm{Ca}^{2+}$. If the series $\mathrm{Ca}<\mathrm{Li}<\mathrm{Cs}<\mathrm{Rb}<\mathrm{K}$ $<\mathrm{Na}$ is found for reversal of charge of a phosphate colloid, the salt with the lower reversal of charge concentration (e.g. $\mathrm{LiCl}$ ) will exhibit a lower antagonism curve than the salt with a higher reversal of charge concentration (e.g. $\mathrm{NaCl}$ ). This is due to the fact that the former alkali cation is more readily fixed to the colloid than the latter, so that cation fixation already begins to interfere at a lower concentration. In the case of egg cells it has been argued above that the height of the antagonism curves at $B$ is mainly determined by the osmotic value of the medium. For that reason the height 
of the antagonism curves at $B$ does not reflect the effectivity of fixation of the different alkali cations. At low concentrations a similar interaction curve for all alkali chlorides would be found, because the added chloride ions will play the same part in all cases, and the concentrations of the cations are still too small to have an influence on the charge of the colloid. This is indeed the case, as shown in Fig. 7. The fixation of alkali metal ions becomes apparent at higher concentrations, however. As shown in Fig. 7, the curves turn off from the isosmotic line at very different concentrations; once again the series $\mathrm{I} \mathbf{i}<\mathrm{Cs}<\mathrm{K}<\mathrm{Na}$ is found, indicating a typical sequence which is characteristic of phosphate colloids in vitro. However, the concentrations of the alkali chlorides found are low compared with the concentrations found in in vitro experiments for reversal of charge of phosphate colloids. This is clear from the fact that phosphate colloids in a cell, present in, for example, membrane structures, are functional. Only a strictly determined state of charge of the phosphate colloid depending on $\mathrm{Ca}$ ions will guarantee the normal function of membranes [4]. Thus a living egg cell will be very sensitive with regard to fixation of cations in competition with Ca. With developing egg cells the fixation of cations will already become apparent at a much lower concentration level than in in vitro experiments, in which reversal of charge is determined.

EFFects of alkali ChLorides and the interaction with $\mathrm{CaCl}_{2}$. On p. 466 a hypothesis was formulated for the action of alkali salts when applied to the egg. Alkali metal ions are fixed on a phosphate colloid in competition with $\mathrm{Ca}^{2+}$ present in the cell membrane. The effectivity of fixation at equal concentrations of alkali metal ions in the medium decreases in the order $\mathrm{Li}>\mathrm{Cs}>\mathrm{Rb}>\mathrm{K}>\mathrm{Na}$, which is the inverse order of the reversal of charge concentrations. If this hypothesis is valid, it is obvious that addition of $\mathrm{Ca}^{2+}$ to a medium with a noxious alkali chloride concentration will be favourable to the egg cell. This effect should be observed with all alkali ions, and is in fact found. The effectivity of fixation of the alkali metal ions will also determine the point $\mathrm{C}$ of the antagonism curves. At a certain concentration of alkali ions a further increase of $\mathrm{CaCl}_{2}$ will no longer exclude the fixation of alkali cations. The series $\mathrm{Li}<\mathrm{Cs}<\mathrm{K}<\mathrm{Na}$ is found, which is according to expectation.

In the first paragraph of the discussion attention was drawn to the $\mathrm{CaCl}_{2}$ concentrations which accompany maximal antagonism at $\mathrm{C}$.

The series [Ca] $\mathrm{NaCl}<$ [Ca] $\mathrm{LiCl}<[\mathrm{Ca}] \mathrm{CsCl}<[\mathrm{Ca}] \mathrm{KCl}$ is found. Furthermore the shape of part $\mathrm{D}-\mathrm{C}$ is distinctly different if $\mathrm{Na}$ and $\mathrm{Li}$, on the one hand, are compared with $\mathrm{K}$ and $\mathrm{Cs}$, on the other. This may be understood 
in the following way. Bungenberg de Jong et al. (11] p. 287) explain the "transition series" of alkali ions found for phosphate colloids by the interplay of valency, radius and polarizing power of the cations and the polarizability of the negatively charged ionized groups of the colloid in an aqueous environment. They write the sequence $\mathrm{Li}<\mathrm{Cs}<\mathrm{Rb}<\mathrm{Na}<\mathrm{K}$ as follows:

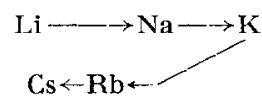

The fixation of the cations on negatively charged ionized groups is determined by Coulomb energy and polarization energy. In case of the phosphate colloids with a polarizability greater than water both energies will be added and $\mathrm{Li}$ will add more polarization energy than the bigger $\mathrm{Na}$ and $\mathrm{K}$ ions. The sequence $\mathrm{Li}<\mathrm{Na}<\mathrm{K}$ is expected. The large $\mathrm{Cs}$ and $\mathrm{Rb}$ ions have, because of their large radius, too small a field strength to show polarizing action. For these ions the sequence $\mathrm{Cs}<\mathrm{Rb}<\mathrm{K}$ must thus be expected, as it is determined by the hydration. In experiments with Limnaea eggs the sequence $\mathrm{Li}<\mathrm{Cs}<\mathrm{Rb}<\mathrm{K}<\mathrm{Na}$ is found for death rate. This series can be written

$$
\mathrm{Li} \longrightarrow \mathrm{Cs} \leftarrow \mathrm{Rb} \leftarrow \mathrm{K} \leftarrow \text { Na }
$$

It is found furthermore that upon addition of $\mathrm{Ca}^{2+}$ to the medium the effective concentrations of the alkali ions are higher than without $\mathrm{CaCl}_{2}$. As was mentioned above for $\mathrm{Li}^{+}$and $\mathrm{Na}^{+}$, this antagonism occurs at lower concentrations of $\mathrm{CaCl}_{2}$ than with $\mathrm{Cs}^{+}$and $\mathrm{K}^{+}$. This may be explained by the differences between $\mathrm{Li}^{+}$and $\mathrm{Na}^{+}$, on the one hand, and $\mathrm{Cs}^{+}$and $\mathrm{K}^{+}$, on the other, with regard to fixation at a phosphate colloid in the presence of $\mathrm{Ca}^{2+}$ ions. In the first case polarization energy relations are predominant, in the latter case the radius and the concomitant very low or absent polarizing energies of the ions will be predominant. It can be envisaged that in both cases different phenomena play a part with respect to $\mathrm{Ca}^{2+}$ interaction; and that $\mathrm{Ca}^{2+}$ interaction occurs at different concentration values.

Viability and ion interaction.--In the foregoing pages 50 per cent death of embryos has been used as a criterion. If normal development is considered, it is obvious from Figs. 3-6 that the interaction phenomena are similar to those found for death rate. A difference between $\mathrm{LiCl}$ and the other alkali chlorides is observed with regard to exogastrulation. With Li most of the combinations within the area of the isothanate give a high percentage of exogastrulation, while with the other alkali cations exogastrulae are much less numerous and occur only in a small zone of combinalions. Here again the 
explanation may be found in the differences in polarizing power and radius of the alkali ions, because $\mathrm{Li}^{+}$has the strongest polarizing power and the smallest radius. A further argument for this may be that within the group of alkaline earth ions, with regard to exogastrulation, $\mathrm{Be}^{2+}$ shows the same peculiarity as $\mathrm{Li}^{2+}$ in the group of alkali metal ions (unpublished observations).

Site of action of the alkali metal ions.-From the experiments it seems evident that the primary action of alkali metal ions is an interaction with phosphate colloids. This group of compounds comprises all kinds of phosphatides and nucleates. There is hardly any part in the egg cell which is devoid of phosphate colloids, and there is hardly any process in which they may not play a part. Along this line it is impossible to come to a conclusion on the site of action of the ions, but it would be of importance if we could only discriminate between nuclear, cytoplasmic or surface action of the ions.

From the studies of morphogenesis following treatment of eggs with $\mathrm{LiCl}$, cortical field theories have emerged which state that development is governed by a graded distribution of cortical factors [5]. In this reasoning the action of ions is assumed to be localized at the cell surface $[3,4,8]$. As a matter of fact it is still an open question whether the ions penetrate into Limnaea eggs at early developmental stages [3].

However, the egg might prove to be permeable to ions and to deal with them actively, both on their way in or, once they are in, when pumping them out. If the phosphate colloids which are acted upon by the ions are not located in the surface but in the cell interior, it would be all the more remark able that the aforementioned interactions have been found, because the environment of the phosphate colloid is a much more complex one inside the egg than the cell surface. Obviously a study of the internal ionic environment as a function of the external is highly desirable.

Concluding remarks.--It seems reasonable to assume that if in Limnaea eggs "simple" interaction phenomena occur between phosphate colloids, calcium and alkali metal ions, this type of interaction will play a part in all kinds of cells.

Therefore, in studies in which the ionic composition of the cell environment or the medium of cellular particles play a part, it will be important to consider interactions of ions in relation to the ever-present phosphate colloid complexes. It could very well be that many conflicting results in cytology and cell physiology can be traced back to the incomplete standardization of ion interactions.

Above all the results have shown the considerable importance of the cell- 
environment relations for normal development, and a line along which correct standardizations of these relations may be obtained.

\section{SUMMARY}

1. The action and interaction of $\mathrm{CaCl}_{2}$ and alkali chlorides on eggs of Limnaea stagnalis have been studied.

2. $\mathrm{CaCl}_{2}$ antagonizes death caused by alkali chlorides. The number of normally developing embryos increases in all cases.

3. Alkali chlorides antagonize death caused by $\mathrm{CaCl}_{2}$. With $\mathrm{NaCl}, \mathrm{KCl}$ and $\mathrm{CsCl}$ the number of normally developing embryos increases; with $\mathrm{LiCl}$ normal development is promoted only to a small extent, but instead many exogastrulae are found.

4. The reciprocal antagonism between $\mathrm{CaCl}_{2}$, on the one hand, and $\mathrm{LiCl}$, $\mathrm{NaCl}, \mathrm{KCl}$ and $\mathrm{CsCl}$, respectively, on the other, with regard to normal and abnormal development or death gives rise to similar isothanates 50 .

5. The reciprocal antagonism between $\mathrm{CaCl}_{2}$ and alkali chlorides can be explained by their influence on phosphatides. The phosphatides of the cell membrane are considered to be of primary importance in this context.

\section{REFERENCES}

1. Bungenberg de Jong, H. G., Colloid Science vol. 2, H. R. Kruyt (ed.) Elsevier Publ. Comp., Inc. Amsterdam, 1949.

2. Elbers, P. F., Proc. Kon. Ned. Akad. Wel. G 55, 74 (1952).

3. — Thesis Utrecht, 1959.

4. Geilenkirchen, W. L. M., Thesis Utrecht, 1961.

5. Raven, Chr. P., Proc. Kon. Ned. Akad. Wet. 45, 856, 1942.

6. — Arch. Néerl. Zool. 7, 353, 1946.

7. — J. exptl Zool. 121, 1 (1952).

8. - (in collaboration with A. C. Drinkwaard, J. Haeck, N. H. Verdonk and L. A. Verhoeven), Publ. Staz. Zool. Napoli 28, 136 (1956).

9. Raven, Chr, P. and Bretschneider, L. H., Arch. Néerl. Zool. 6, 255 (1942).

10. Raven, Chr. P. and Klomp, H., Proc. Kon. Ned. Akad. Wet. 49, 101 (1946).

11. Vries, L. G. De, Proc. Kon. Ned. Akad. Wet. G 56, 584 (1953). 